\title{
Intermediate Chondrogenic Neoplasm
}

National Cancer Institute

\section{Source}

National Cancer Institute. Intermediate Chondrogenic Neoplasm. NCI Thesaurus. Code C121846.

A locally aggressive or rarely metastasizing cartilag inous matrix-producing neoplasm characterized by the presence of neoplastic chondrocytes. 